\title{
Recommendations of the treat-and-
} extend regimen for neovascular agerelated macular degeneration: 2020 updates

Alvin KH Kwok ${ }^{l}, M D(H K), M D(C U H K), P h D(H K), F R C S(E d i n)$, FRCOphth(UK), FCOphthHK, FHKAM(Ophth); Wai-Ching Lam ${ }^{2}$, MD, FRCS(C); Angie HC Fong ${ }^{3}$, MBBS, MPH(HK), FCOphthHK, FHKAM(Ophth); Nicholas SK Fung ${ }^{2}, M B C h B, M R C S(E d i n), F C O p h t h H K$, FHKAM(Ophth); Mary Ho ${ }^{4}, M B C h B, M S c, F C O p h t h H K$, FHKAM(Ophth); Lawrence PL Iu ${ }^{4}$, MBBS, MPH(HK), FRCSEd(Ophth), FRCS(Glasg), FCOphthHK, FHKAM(Ophth); Callie KL Ko ${ }^{5}$, MBBS, MRCSEd(Ophth), FCOphthHK, FHKAM(Ophth); Shaheeda Mohamed ${ }^{3}$, MBBS, MPH, MMed, FRCS(Edin), FRCOphth, FCOphthHK, FHKAM(Ophth); Danny SC Ng ${ }^{4}$, MBBS, MPH, FRCS(Edin), FCOphthHK, FHKAM(Ophth); Heather HY Tang ${ }^{6}$, MBChB, MSc, FRCS(Edin), FCOphthHK, FHKAM(Ophth); Ian YH Wong ${ }^{1}$, MBBS(HK), MMed(Ophth), MD(HK), FRCSEd(Ophth), FRCOphth, FRCS(Glasg), FCOphthHK, FHKAM(Ophth); Raymond LM Wong ${ }^{7}$, MBBS, MRCSEd(Ophth), FCOphthHK, FHKAM(Ophth); Timothy YY Lai ${ }^{4,8}$, MD(CUHK), FRCSEd(Ophth), FRCOphth, FCOphthHK, FHKAM(Ophth) ${ }^{\prime}$ Hong Kong Sanatorium \& Hospital, Hong Kong

${ }^{2}$ Department of Ophthalmology, The University of Hong Kong, Hong Kong

${ }^{3}$ Hong Kong Eye Hospital, Hong Kong

${ }^{4}$ Department of Ophthalmology \& Visual Sciences, Prince of Wales Hospital, Hong Kong

${ }^{5}$ Department of Ophthalmology, Tung Wah Eastern Hospital, Hong Kong

${ }^{6}$ Department of Ophthalmology, United Christian Hospital, Hong Kong

${ }^{7}$ Hong Kong C-MER Dennis Lam \& Partners Eye Center, Hong Kong

82010 Eye \& Cataract Centre, Hong Kong

Correspondence and reprint requests:

Timothy YY Lai, Department of Ophthalmology \& Visual Sciences, The Chinese University of Hong Kong, Hong Kong.Email: tyylai@cuhk.edu.hk

\section{Abstract}

Anti-vascular endothelial growth factor (anti-VEGF) treatment is the gold standard of care for neovascular age-related macular degeneration (nAMD). To strike a balance between treatment burden and vision improvement, a treat-and-extend (T\&E) regimen is the preferred approach to administer anti-VEGF treatment.

To facilitate implementation of the T\&E regimen for nAMD in Hong Kong, a panel of retinal experts, with the support of Bayer Healthcare, held an online meeting on 15 September 2020 to discuss the latest published evidence and clinical experiences regarding the suitability and safety of anti-VEGF agents in the $\mathrm{T} \& \mathrm{E}$ regimen, patient selection, retreatment criteria, considerations for treatment discontinuation, and barriers to implementing the $\mathrm{T} \& \mathrm{E}$ regimen.

Compared with the 2019 recommendations, this 2020 version contains several major updates including differentiation of fluid compartments in retreatment criteria, additional considerations for patient selection, streamlined criteria for treatment cessation, and applicability of the T\&E regimen in patients with polypoidal choroidal vasculopathy (PCV).

These updated recommendations are expected to facilitate implementation of the T\&E regimen for nAMD including PCV in Hong Kong, with the aims of improving patient visual acuity, lowering treatment burden, and facilitating service capacity planning over the long term.

Key words: Macular degeneration; Retina; Subretinal fluid 


\section{Introduction}

Neovascular age-related macular degeneration (nAMD) develops when chronic degenerative and hypoxic retina releases cytokines including vascular endothelial growth factor (VEGF) and placental growth factor (PGF), which act on VEGF receptors-1 and -2 to trigger downstream effects such as inflammation, vascular leakage, and pathological neovascularization. ${ }^{1}$ Current evidence suggests that choroidal ischemia may play a role in the pathogenesis of nAMD. ${ }^{2}$ Age-related macular degeneration is the leading cause of legal blindness in adults aged $>60$ years, affecting around 196 million people worldwide. ${ }^{3}$ In 2010, it was estimated that about 3000 new cases of nAMD develop in Hong Kong each year. ${ }^{4}$ This number is expected to increase with an aging population.

The gold standard in nAMD management is intravitreal anti-VEGF injection, which used to be in a monthly fixeddosing injection interval. ${ }^{5-7}$ With the chronic progressive nature of nAMD, persistent monthly intravitreal injections pose a heavy treatment burden on both ophthalmologists and patients. ${ }^{8}$ The PrONTO study was conducted to investigate an alternative reactive as-needed (pro re nata) regimen, in which injections are given in response to disease worsening based on regular monthly monitoring for predetermined visual acuity and/or anatomical criteria. ${ }^{9}$ The results shed light on the possibility of lowering treatment burden. ${ }^{9}$

The subsequent SUSTAIN, CATT, and IVAN studies reevaluated the pro re nata regimen but failed to replicate the positive outcomes of the PrONTO study. ${ }^{10-12}$ In view of the mixed results, a proactive individualized treat-and-extend (T\&E) regimen was proposed, with the aim of achieving similar visual acuity gain with fewer clinic visits, compared with regular monthly dosing. ${ }^{13}$ The principle of the T\&E regimen is to administer injections at individualized intervals based on visual acuity and/or anatomical response, with no monitoring visits required..$^{13}$

Patients with nAMD require constant treatment to maintain vision outcomes, as treatment discontinuation is associated with lesion reactivation and visual acuity loss in the long term. ${ }^{14,15}$ Maintenance of vision gains in treated patients is poor over time, and may be worsened with fewer antiVEGF injections administered. ${ }^{16}$ The pro re nata regimen is associated with undertreatment and poorer visual outcomes, compared with a fixed-dosing regimen. ${ }^{17,18}$ To strike a balance between treatment burden and vision improvement, the $\mathrm{T} \& \mathrm{E}$ regimen requires fewer injections but with no signs of undertreatment (compared with a fixed-dosing regimen) $)^{19-22}$ and improves visual outcomes with fewer clinic visits (compared with a pro re nata regimen). ${ }^{23}$

The T\&E regimen allows for predictable and reduced numbers and frequency of clinic visits and facilitates service allocation (eg, arrangement of optical coherence tomography [OCT]) and reduces workload of healthcare professionals, particularly during the COVID-19 pandemic.
At the same time, patients can receive more timely treatment, with the potential to reduce time for clinic visits and treatment cost in the long run, compared with a fixed-dosing regimen. Nonetheless, financial constraints, psychological unpreparedness, and fatigue from receiving a series of injections may refrain patients from choosing the T\&E regimen. To facilitate implementation of the T\&E regimen, clear recommendations on a treatment pathway with clinical and logistical details should be established.

On 15 September 2020, with the support of Bayer Healthcare, an expert panel of ophthalmologists from public, private, and academic institutions in Hong Kong held an online meeting to discuss the suitability and safety of anti-VEGF agents in the $T \& E$ regimen, retreatment criteria, surrogate markers for treatment decision-making, roles of fluid compartments, considerations for treatment discontinuation, and obstacles to the implementation of the T\&E regimen. Based on the latest published evidence and expert opinions, the 2020 updated recommendations for practicing the T\&E regimen for nAMD including polypoidal choroidal vasculopathy (PCV) was established, based on the recommendations in 2019. ${ }^{24}$

\section{Recommendations}

\section{Logistics of a T\&E clinic}

The logistics of a T\&E clinic include: (1) checking for visual acuity, (2) performing an OCT test, (3) reviewing the patient condition by an ophthalmologist, (4) administering an injection, and (5) deciding on the next appointment for treatment, with the interval reduced, maintained, or extended.

\section{Updates to previous recommendations}

Items in the 2019 recommendations that are kept include the three initial monthly injections in the loading phase, the maximum injection interval of 16 weeks, and one of the criteria for extending the treatment interval (ie, no loss of $\geq 5$ letters of the Early Treatment Diabetic Retinopathy Study [ETDRS]).

The T\&E pathway is revised to illustrate more clearly whether to extend, maintain, or shorten the treatment interval as per visual acuity and anatomical criteria, which are modified based on the latest studies.$^{25,26}$ In particular, this update allows the possibility to extend the treatment interval with some tolerance of stable subretinal fluid (SRF) if there is ongoing anti-VEGF therapy. The minimum injection interval is changed from 4 weeks to 8 weeks, and treatment interval adjustment is recommended at 2-/4-week interval, instead of $1 / 2 / 4$ weeks in the previous recommendation. ${ }^{24}$

Regarding considerations for treatment cessation, the previous recommendations suggested the need for 2 to 3 years of treatment and indefinite monitoring after treatment discontinuation. ${ }^{24}$ The 2020 update recommends that treatment cessation can be considered in patients who are stable on anti-VEGF therapy every 16 weeks (q16w) for 


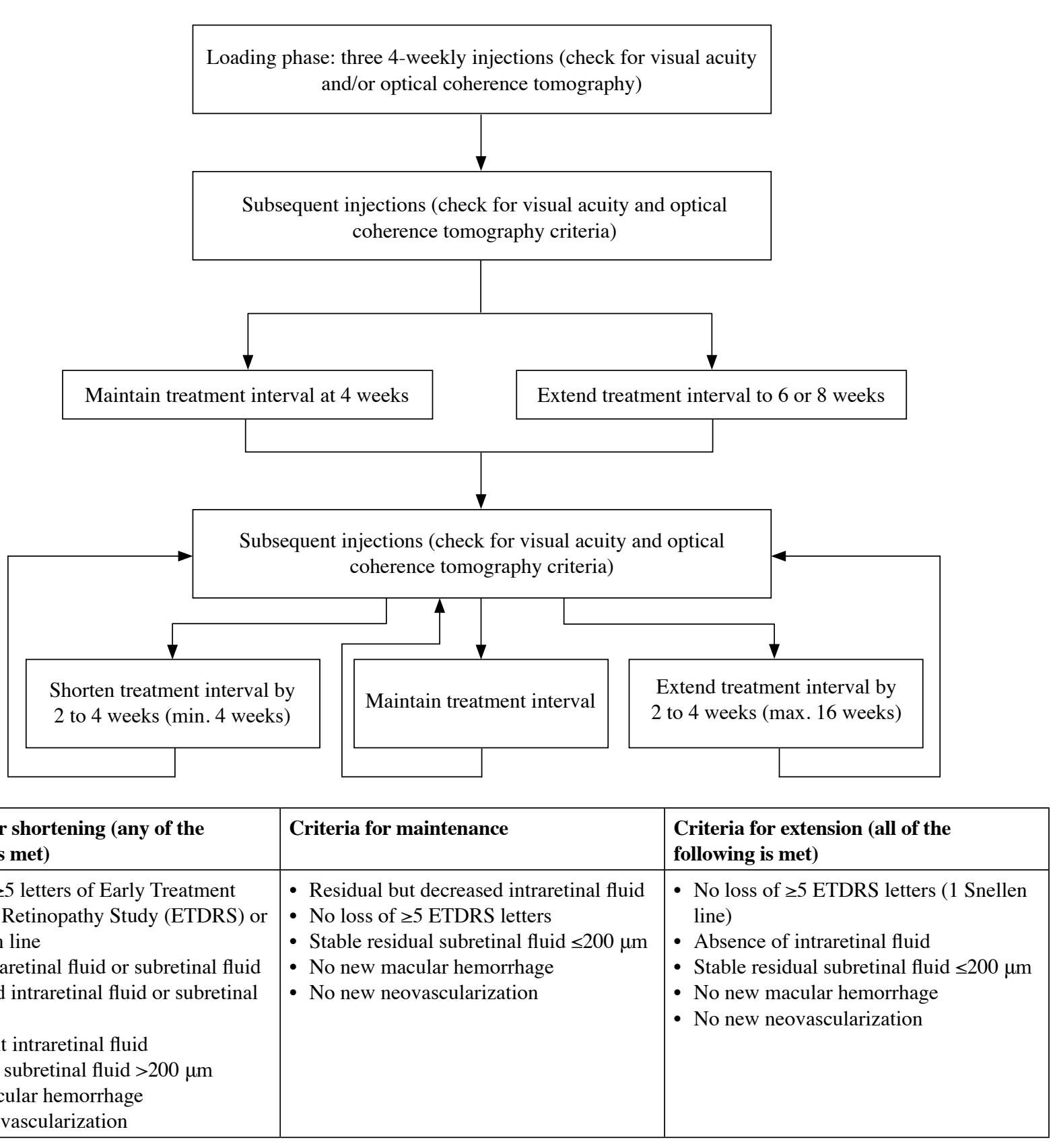

Figure. Proposed treat-and-extend regimen using intravitreal anti-vascular endothelial growth factor (anti-VEGF) therapy for the treatment of neovascular age-related macular degeneration and polypoidal choroidal vasculopathy.

1 year (ie, three injections), with 1-year post-cessation observation, which is in line with the recommendations by a UK expert panel. ${ }^{27}$

For patient selection, the 2020 update recommends that, in addition to single-eye patients, the T\&E regimen should be considered in patients who have good visual acuity outcomes after three loading doses.

Three new sections are added. One discusses the relationships between molecular properties of an anti-VEGF agent and its duration of action, which is an important factor in choosing a suitable agent for use in the T\&E regimen. Another new section reviews safety profiles of anti-VEGF agents based on data from clinical studies and post-marketing experience. The third new section explains the applicability of the T\&E regimen in patients with $\mathrm{PCV}$.

With respect to the limitations of the T\&E regimen, the practical issues on the implementation of the regimen in routine clinical practice (including financial considerations, resource limitations, and patient psychology) are discussed, as are strategies to boost the acceptance of the T\&E regimen among patients. 


\section{Loading phase}

Consistent with the previous recommendations, the expert panel recommends using three monthly injections in the loading phase. ${ }^{24}$ The first injection is preferably administered on the day of OCT assessment. In the two subsequent visits, visual acuity and clinical status should be assessed, and OCT may not be required, because imaging results are not expected to change the treatment plan during the loading phase. Refraining from OCT may help to reserve service capacity and reduce patients' waiting time.

Four to eight weeks after the last loading dose, another injection can be administered depending on the patients' clinical performance, based on the set of extension/ maintenance/shortening criteria. Both visual acuity and OCT should be checked to determine the next treatment interval.

\section{Extension of treatment interval}

At every subsequent visit, both visual acuity and OCT should be checked to determine whether the treatment interval should be extended, maintained, or shortened. Intraretinal fluid (IRF), visual acuity (in terms of ETDRS letters), new onset of macular hemorrhage, and neovascularization are the criteria for guiding the treatment interval, based on evidence from the FLUID and ALTAIR trials..$^{25,26}$

Compared with visual acuity, intraretinal fluid is a more important surrogate marker for treatment decision-making because accumulation of fluid often occurs before visual acuity loss. In post hoc analyses of the CATT, IVAN, HAWK, and HARRIER trials, higher fluctuation of central subfield thickness is associated with more losses in visual acuity. ${ }^{11,12,28}$ However, most panelists note that greater overall fluid resolution does not directly translate to better visual outcomes in nAMD. They recognize the significance of differentiating fluid compartments and suggest that IRF, rather than SRF, has a direct impact on visual acuity outcomes. A completely dry retina may not be necessary in $\mathrm{nAMD}$ management because the presence of IRF is associated with worse visual acuity over time, and residual SRF appears to have neutral or even protective effects on visual outcomes..$^{11,25,29-31}$ Although the exact mechanism is unclear, the presence of SRF is hypothesized to reduce the risk of vision-threatening macular atrophy. ${ }^{11}$ Nonetheless, eyes with residual SRF are still receiving ongoing antiVEGF therapy, and treatment should be continued in nAMD eyes with SRF.

In the FLUID trial of ranibizumab, ${ }^{25}$ a T\&E regimen that tolerated an SRF of $\leq 200 \mu \mathrm{m}$ yielded non-inferior visual acuity outcomes, with fewer injections, compared with the more aggressive $T \& E$ regimen, which did not tolerate SRF. In the ARIES study that examined the early-start and late-start T\&E regimen arms with aflibercept also showed that a treatment interval extension in eyes with an SRF of $\leq 50 \mu \mathrm{m}$ could maintain robust visual acuity gain, and thus a dry retina may not be necessary. ${ }^{32}$ The expert panel recommends that residual SRF can be tolerated and allowable for extending the treatment interval in a T\&E regimen, with the aim of reducing treatment burden. $45.45 \%$ of panelists preferred to adopt a threshold of residual SRF of $\leq 200 \mu \mathrm{m}$ (whereas $36.36 \%$ preferred $\leq 100 \mu \mathrm{m}$ and $18.18 \%$ preferred $\leq 50 \mu \mathrm{m})$, based on the FLUID trial that supports reducing injection numbers and the treatment burden for patients while maintaining visual acuity. Different from residual SRF, a new onset of or an increase in SRF can be a sign of disease recurrence, which warrants shortening the treatment interval. SRF tolerance is only applicable to a $T \& E$ regimen. In the pro re nata treatment, any fluid should be treated completely and should aim for complete dryness to prevent progressive damage.

In the ALTAIR study, ${ }^{26}$ aflibercept T\&E regimens with 2- and 4-week extensions yielded similar visual and anatomical outcomes. $66.7 \%$ of the panelists recommended extending the treatment interval by 2 weeks, which is a more conservative and appropriate approach because many Hong Kong patients on a T\&E regimen have only one functional seeing eye based on the panelists' clinical experiences. The remaining panelists suggested extending by 4 weeks $(16.7 \%)$ or depending on clinical judgment $(16.7 \%)$. The panel recommends extending the treatment interval by 2 weeks (up to 16 weeks) when the following criteria are fulfilled as per OCT and visual acuity assessments: (1) no loss of $\geq 5$ ETDRS letters (1 Snellen line), (2) no residual IRF, (3) stable residual SRF of $\leq 200 \mu \mathrm{m}$, (4) no new macular hemorrhage, and (5) no new neovascularization (as per OCT angiography).

\section{Reduction of treatment interval}

In patients without any signs of disease recurrence (ie, loss of $\geq 5$ ETDRS letters, new IRF or SRF, increased IRF or SRF, persistent IRF, residual SRF $>200 \mu \mathrm{m}$, new macular hemorrhage, or new neovascularization), the treatment interval should be shortened by 2 weeks (the minimum injection interval is 4 weeks). In line with previous recommendations, no treatment is required for intraretinal cysts secondary to chronic multiple injections, which tend to be small on serial OCT scans compared with the development of IRF. An increase in fluid associated with pigment epithelial detachment may not necessarily lead to shortening of the treatment interval but should be monitored carefully.

\section{Maintenance criteria}

In patients with residual but decreased IRF and no other signs of disease reactivation (ie, no loss of $\geq 5$ ETDRS letters, residual $\mathrm{SRF} \leq 200 \mu \mathrm{m}$, no new macular hemorrhage, and no new neovascularization), the treatment interval should not be extended but can be maintained.

\section{Cessation of treatment}

Anti-VEGF therapy is associated with atrophy development, but it remains uncertain whether treatment burden or duration are causes. ${ }^{33-35}$ The expert panel recommends that treatment discontinuation should be considered in patients who are stable on 16-weekly anti-VEGF therapy 
for 1 year (ie, three injections per year), with the aim to reduce treatment burden. In view of the risks of disease reactivation and vision loss with undertreatment, ${ }^{36}$ patients, especially those with a single functional eye, should be observed prudently for disease stability for 1 year after treatment discontinuation. Before deciding on cessation of treatment, clinicians should have a thorough discussion with patients on the risk-benefit balance. If patients refuse to stop treatment or encounter disease recurrence, 16-weekly anti-VEGF treatment should be maintained or initiated.

\section{Selection of patients}

Consistent with previous recommendations, the expert panel recommends using a $T \& E$ regimen in single-eye patients. A T\&E regimen should be considered in patients who have good visual acuity outcomes after three loading doses, whereas patients with anti-VEGF-refractory nAMD (stationary or increased intraretinal or subretinal exudation despite more than three consecutive injections) or at younger ages (eg $<70$ years) may not be prioritized to receive a $T \& E$ regimen, because of a lack of relevant evidence, given that the mean ages of participants in the FLUID and ALTAIR studies were 79 and 74 years, respectively. ${ }^{25,26}$

\section{Choice of anti-VEGF agents}

The expert panel recommends that anatomical efficacy, visual efficacy, durability of action, and safety are factors that affect the uptake of an anti-VEGF agent in clinical decision-making. With respect to both anatomical and visual efficacy of an anti-VEGF agent, the binding affinity, potency, and intravitreal half-life are considered important contributors, as are the roles of molecular size and molar dose, as all molecular properties are closely related. The intravitreal half-life of an agent is the major determinant of its durability of action, while other molecular properties also play certain roles.

In Hong Kong, current licensed anti-VEGF agents for nAMD include ranibizumab and aflibercept $;{ }^{37}$ brolucizumab may be approved in future as it has been approved in the USA and several developed countries. ${ }^{38}$ Aflibercept has distinct molecular properties. Compared with ranibizumab and brolucizumab, aflibercept has higher binding affinity, ${ }^{39,40}$ potency, ${ }^{41}$ and estimated intravitreal half-life, ${ }^{42-44}$ contributing to a longer estimated VEGF suppression time (ie, 71 days). ${ }^{45-48}$

\section{Safety of anti-VEGF agents}

The most common adverse reactions with intravitreal anti-VEGF therapy include conjunctival hemorrhage, reduced visual acuity, eye pain, cataract, and increased intraocular pressure..$^{20,26}$ Rates of serious adverse events such as intraocular inflammation and endophthalmitis are consistently low across a series of phase III trials of both aflibercept and ranibizumab. ${ }^{49}$ Around 30 million vials of aflibercept have been sold globally; rates of retinal artery occlusion and/or retinal vasculitis are very low. ${ }^{50}$ Such serious adverse events are rarely reported $(0.1 \%)$ in patients treated with ranibizumab. ${ }^{51}$ Newer anti-VEGF agents such as abicipar pegol ${ }^{52}$ and brolucizumab ${ }^{53,54}$ might be associated with increased risks of intraocular inflammation, retinal artery occlusion, and retinal vasculitis. This indicates the heterogeneity in safety profiles among the drug class. Larger molecules with Fc fragments have a longer systemic half-life, which possibly leads to a lower serum VEGF concentration and higher risk of systemic adverse effects. ${ }^{55}$ However, no data support a clinical correlation between the systemic half-life and the risk of VEGF-related adverse effects. A comprehensive review reported that rates of ocular and systemic adverse events with aflibercept were low and similar to those of the control arm. ${ }^{56}$

\section{Applicability of a T\&E regimen to $\mathrm{PCV}$}

PCV, a subtype of nAMD, is particularly common in Asians. ${ }^{57}$ The expert panel recommends that PCV can be treated with the T\&E regimen. In the PLANET phase IIIb/IV trial, aflibercept monotherapy was noninferior to aflibercept plus photodynamic therapy in terms of improvements in visual acuity at weeks 52 and $96 .^{58,59}$ The T\&E regimens have similar efficacy for typical nAMD and PCV. ${ }^{60,61}$ Clinical experiences have also demonstrated the efficacy and safety of T\&E regimens of aflibercept in patients with PCV. ${ }^{62-64}$

\section{Limitations of a $T \& E$ regimen}

Because of manpower and resource limitations, most public hospitals in Hong Kong do not go directly for a T\&E regimen after the loading phase. In clinical practice of most panelists, a T\&E regimen is offered to as many patients with typical nAMD or PCV as possible, but only $<30 \%$ of patients are actively treated with a $T \& E$ regimen, because of the inability to do the injection and follow-up visit on the same day and the high treatment cost. Most patients who are actively treated with a T\&E regimen are eligible for free treatment (eg civil servants or participants of a Hospital Authority special program that targets low-income or single-eye patients). Non-adherence to a T\&E regimen is due to financial constraints, fatigue, and psychological unpreparedness for chronic management.

\section{Conclusion}

We recommended a $\mathrm{T} \& \mathrm{E}$ regimen for $\mathrm{nAMD}$ including PCV based on the latest clinical evidence and shared experiences. Compared with the pro re nata approach, the T\&E regimen is expected to improve visual acuity, lower treatment burden, and facilitate service capacity planning in the long run.

\section{Contributors}

All authors contributed to the concept/design, acquisition of data, analysis/interpretation of data, drafting of the manuscript, and critical revision for important intellectual content. All authors had full access to the data, contributed to the study, approved the final version for publication, and take responsibility for its accuracy and integrity. 


\section{Conflict of interest}

Alvin Kwok has received lecture fees from Bayer and Novartis. Timothy Lai has received consultancy honoraria and lecture fees from AbbVie, Allergan, Bayer, Genentech, Heidelberg Engineering, Novartis Pharmaceuticals, Oculis, and Roche. Wai-Ching Lam has received consultancy honoraria and lecture fees from Alcon, Bayer, and Novartis. Raymond Wong has received lecture fees from Bayer and Novartis. Other authors have no conflicts of interest to disclose.

\section{Funding/support}

Medical writing was funded by Bayer HealthCare Limited, Hong Kong in accordance with Good Publication Practice guidelines (http://www.ismpp.org/gpp3).

\section{Data availability}

All data generated or analyzed during the present study are available from the corresponding author on reasonable request.

\section{Acknowledgments}

The authors thank Mr CT Tsoi of Best Solution Company Limited, Hong Kong for providing medical writing support/editorial support in drafting the manuscript. The authors also thank Prof Michael W Stewart (Department of Ophthalmology, Mayo Clinic, USA) for sharing the latest clinical evidence and facilitating the panel discussions.

\section{References}

1. Cao Y. Positive and negative modulation of angiogenesis by VEGFR1 ligands. Sci Signal 2009;2:re1. Crossref

2. Chirco KR, Sohn EH, Stone EM, Tucker BA, Mullins RF. Structural and molecular changes in the aging choroid: implications for age-related macular degeneration. Eye (Lond) 2017;31:10-25. Crossref

3. Wong WL, Su X, Li X, et al. Global prevalence of age-related macular degeneration and disease burden projection for 2020 and 2040: a systematic review and meta-analysis. Lancet Glob Health 2014;2:e106-16. Crossref

4. LCQ14: Treatment for age-related macular degeneration. Available from: https://www.info.gov.hk/gial general/201003/10/P201003100138_print.htm. Accessed 8 December 2020.

5. Rosenfeld PJ, Brown DM, Heier JS, et al. Ranibizumab for neovascular age-related macular degeneration. $N$ Engl $J$ Med 2006;355:1419-31. Crossref

6. Brown DM, Kaiser PK, Michels M, et al. Ranibizumab versus verteporfin for neovascular age-related macular degeneration. N Engl J Med 2006;355:1432-44. Crossref

7. Schmidt-Erfurth U, Chong V, Loewenstein A, et al. Guidelines for the management of neovascular age-related macular degeneration by the European Society of Retina Specialists (EURETINA). Br J Ophthalmol 2014;98:1144-67. Crossref

8. Chakravarthy $U$, Evans J, Rosenfeld PJ.Age related macular degeneration. BMJ 2010;340:c981. Crossref

9. Fung AE, Lalwani GA, Rosenfeld PJ, et al. An optical coherence tomography-guided, variable dosing regimen with intravitreal ranibizumab (Lucentis) for neovascular age-related macular degeneration. Am J Ophthalmol 2007; 143:566-83. Crossref

10. Holz FG, Amoaku W, Donate J, et al. Safety and efficacy of a flexible dosing regimen of ranibizumab in neovascular age-related macular degeneration: the SUSTAIN study. Ophthalmology 2011;118:663-71. Crossref

11. Jaffe GJ, Ying GS, Toth CA, et al. Macular morphology and visual acuity in year five of the comparison of age-related macular degeneration treatments trials. Ophthalmology 2019;126:252-60. Crossref

12. Chakravarthy U, Harding SP, Rogers CA, et al. Alternative treatments to inhibit VEGF in age-related choroidal

neovascularisation: 2-year findings of the IVAN randomised controlled trial. Lancet 2013;382:1258-67. Crossref

13. Lanzetta P, Loewenstein A; Vision Academy Steering Committee. Fundamental principles of an anti-VEGF treatment regimen: optimal application of intravitreal antivascular endothelial growth factor therapy of macular diseases. Graefes Arch Clin Exp Ophthalmol 2017;255:125973. crossref

14. Nguyen V, Vaze A, Fraser-Bell S, et al. Outcomes of suspending VEGF inhibitors for neovascular age-related macular degeneration when lesions have been inactive for 3 months. Ophthalmol Retina 2019;3:623-8. Crossref

15. Rofagha S, Bhisitkul RB, Boyer DS, Sadda SR, Zhang $K$; SEVEN-UP Study Group. Seven-year outcomes in ranibizumab-treated patients in ANCHOR, MARINA, and HORIZON: a multicenter cohort study (SEVEN-UP). Ophthalmology 2013;120:2292-9. Crossref

16. Holz FG, Tadayoni R, Beatty $S$, et al. Multi-country reallife experience of anti-vascular endothelial growth factor therapy for wet age-related macular degeneration. $\mathrm{Br} J$ Ophthalmol 2015;99:220-6. Crossref

17. Comparison of Age-related Macular Degeneration Treatments Trials (CATT) Research Group, Maguire MG, Martin DF, et al. Five-year outcomes with anti-vascular endothelial growth factor treatment of neovascular agerelated macular degeneration: the comparison of age-related macular degeneration treatments trials. Ophthalmology 2016;123:1751-61. Crossref

18. Weber M, Velasque L, Coscas F, Faure C, Aubry I, Cohen $S Y$. Effectiveness and safety of intravitreal aflibercept in patients with wet age-related macular degeneration treated in routine clinical practices across France: 12-month outcomes of the RAINBOW study. BMJ Open Ophthalmol 2019;4:e000109. Crossref

19. Richard G, Monés J, Wolf S, et al. Scheduled versus pro re nata dosing in the VIEW trials. Ophthalmology 2015;122:2497-503. Crossref

20. Schmidt-Erfurth $U$, Kaiser $P K$, Korobelnik JF, et al. Intravitreal aflibercept injection for neovascular age-related macular degeneration: ninety-six-week results of the VIEW studies. Ophthalmology 2014;121:193-201. crossref

21. Silva R, Berta A, Larsen $M$, et al. Treat-and-extend versus monthly regimen in neovascular age-related macular 
degeneration: results with ranibizumab from the TREND study. Ophthalmology 2018;125:57-65. Crossref

22. Wykoff CC, Ou WC, Brown DM, et al. Randomized trial of treat-and-extend versus monthly dosing for neovascular agerelated macular degeneration: 2-year results of the TREXAMD Study. Ophthalmol Retina 2017;1:314-21. Crossref

23. Kim LN, Mehta H, Barthelmes D, Nguyen V, Gillies MC. Meta-analysis of real-world outcomes of intravitreal ranibizumab for the treatment of neovascular age-related macular degeneration. Retina 2016;36:1418-31. crossref

24. Wong IY, Ng DS, Fung NS, et al. Treat-and-extend regimen for management of neovascular age-related macular degeneration: recommendations from the Hong Kong Retina Expert Panel. Hong Kong J Ophthalmol 2019;23:159. Crossref

25. Guymer RH, Markey CM, McAllister IL, et al. Tolerating subretinal fluid in neovascular age-related macular degeneration treated with ranibizumab using a treatand-extend regimen: FLUID study 24-month results. Ophthalmology 2019;126:723-34. Crossref

26. Ohji M, Takahashi K, Okada AA, et al. Efficacy and safety of intravitreal aflibercept treat-and-extend regimens in exudative age-related macular degeneration: 52- and 96week findings from ALTAIR: a randomized controlled trial. Adv Ther 2020;37:1173-87. Crossref

27. Ross AH, Downey L, Devonport H, et al. Recommendations by a UK expert panel on an aflibercept treat-and-extend pathway for the treatment of neovascular age-related macular degeneration. Eye (Lond) 2020;34:1825-34. Crossref

28. Dugel PU, Holz FG, Hamilton RD, Jhaveri CD, Singh $R P$, Weissgerber G. Visual and expanded anatomical outcomes for brolucizumab versus aflibercept in patients with neovascular AMD: 96-week data from HAWK and HARRIER. Poster presented at the 13th Asia-Pacific VitreoRetina Society Congress; Shanghai, China. 22-24 November 2019.

29. Schmidt-Erfurth U, Waldstein SM. A paradigm shift in imaging biomarkers in neovascular age-related macular degeneration. Prog Retin Eye Res 2016;50:1-24. crossref

30. Eichenbaum DA. Association between early vision-related quality of life outcomes and anatomic dryness response in neovascular age-related macular degeneration (nAMD): a post-hoc analysis of VIEW trials. Invest Ophthalmol Vis Sci 2019;60:90.

31. Zarbin MA, Stoilov I, Hill L. Anti-VEGF resistant subretinal fluid is associated with reduced risk of macular atrophy and better visual acuity: drug-induced choroidal new vessel homeostasis? Invest Ophthalmol Vis Sci 2020;61:3503. crossref

32. Souied EH, Holz FG, Hykin PG, et al. Efficacy of intravitreal aflibercept treat-and-extend regimen over 2 years for neovascular age-related macular degeneration: ARIES Study. Invest Ophthalmol Vis Sci 2020;61:4210.

33. Li A, Rieveschl NB, Conti FF, et al. Long-term assessment of macular atrophy in patients with age-related macular degeneration receiving anti-vascular endothelial growth factor. Ophthalmol Retina 2018;2:550-7. Crossret

34. Munk MR, Ceklic L, Ebneter A, Huf W, Wolf S, Zinkernagel $M S$. Macular atrophy in patients with long-term anti-VEGF treatment for neovascular age-related macular degeneration. Acta Ophthalmol 2016;94:e757-e764. crossref

35. Sadda SR, Guymer R, Monés JM, Tufail A, Jaffe GJ. Antivascular endothelial growth factor use and atrophy in neovascular age-related macular degeneration: systematic literature review and expert opinion. Ophthalmology
2020;127:648-59. Crossref

36. Mehta H, Tufail A, Daien V, et al. Real-world outcomes in patients with neovascular age-related macular degeneration treated with intravitreal vascular endothelial growth factor inhibitors. Prog Retin Eye Res 2018;65:127-46. Crossref

37. Hospital Authority. Drug formulary. Available from: https://www.ha.org.hk/hadf/Portals/0/Docs/HADF_List/ EL_Full\%20Ver_170708.pdf. Accessed 19 February 2021.

38. Novartis. Novartis completes safety review and initiates update to the Beovu@ prescribing information worldwide. Available from: https://www.novartis.com/news/novartiscompletes-safety-review-and-initiates-update-beovuprescribing-information-worldwide. Accessed 15 October 2020.

39. Papadopoulos N, Martin J, Ruan Q, et al. Binding and neutralization of vascular endothelial growth factor (VEGF) and related ligands by VEGF Trap, ranibizumab and bevacizumab. Angiogenesis 2012;15:171-85. Crossref

40. Gaudreault J, Gunde T, Floyd HS, et al. Preclinical pharmacology and safety of ESBA1008, a single-chain antibody fragment, investigated as potential treatment for age related macular degeneration. Invest Ophthalmol Vis Sci 2012;53:3025

41. U.S. Food and Drug Administration. Drug approval package: Beоvи® (brolucizumab-dbll); non-clinical review(s). Available from: https://www.accessdata.fda.gov/ drugsatfda_docs/nda/2019/761125Orig1s000PharmR.pdf. Accessed 15 October 2020.

42. Do DV, Rhoades W, Nguyen QD. Pharmacokinetic study of intravitreal aflibercept in humans with neovascular agerelated macular degeneration. Retina 2020;40:643-7. Crossref

43. Krohne TU, Liu Z, Holz FG, Meyer CH. Intraocular pharmacokinetics of ranibizumab following a single intravitreal injection in humans. Am $J$ Ophthalmol 2012;154:682-6.e2. Crossref

44. Holz FG, Dugel PU, Weissgerber $G$, et al. Single-chain antibody fragment VEGF inhibitor RTH258 for neovascular age-related macular degeneration: a randomized controlled study. Ophthalmology 2016;123:1080-9. Crossref

45. Stewart MW, Rosenfeld PJ. Predicted biological activity of intravitreal VEGF trap. Br J Ophthalmol 2008;92:667-8. crossref

46. Muether PS, Hermann MM, Dröge K, Kirchhof B, Fauser $S$. Long-term stability of vascular endothelial growth factor suppression time under ranibizumab treatment in age-related macular degeneration. Am J Ophthalmol 2013;156:989-93. e2. Crossref

47. Fauser S, Schwabecker V, Muether PS. Suppression of intraocular vascular endothelial growth factor during aflibercept treatment of age-related macular degeneration. Am J Ophthalmol 2014;158:532-6. crossref

48. Rittenhouse $K$, Ezzine $S$, Eissing $T$, Janer $D$, Katz $T$, Arbour J. Investigating molecular features of aflibercept and brolucizumab to clarify clinical results through pharmacokinetic simulations. Poster presented at the 19th European Society of Retina Specialists Congress; Paris, France. 5-8 September 2019.

49. Plyukhova AA, Budzinskaya MV, Starostin KM, et al. Comparative safety of bevacizumab, ranibizumab, and aflibercept for treatment of neovascular age-related macular degeneration (AMD): a systematic review and network meta-analysis of direct comparative studies. J Clin Med 2020;9:1522. crossref

50. ALTAIR study published confirming efficacy of EYLEA® treat and extend dosing regimens for patients with wet AMD. Available from: https://www.bayer.com/en/ca/news/canada- 
altair-study-confirming-efficacy-eylear-treat-extend-dosing . Accessed 2 November 2021.

51. Woo SJ, Cho GE, Cho JH. Short-term efficacy and safety of ranibizumab for neovascular age-related macular degeneration in the real world: a post-marketing surveillance study. Korean J Ophthalmol 2019;33:150-66. Crossref

52. Kunimoto D, Yoon YH, WykoffCC, et al. Efficacy and safety of Abicipar in neovascular age-related macular degeneration: 52-week results of phase 3 randomized controlled study. Ophthalmology 2020;127:1331-44. Crossref

53. Dugel PU, Singh RP, Koh A, et al. HAWK and HARRIER: ninety-six-week outcomes from the phase 3 trials of brolucizumab for neovascular age-related macular degeneration. Ophthalmology 2021;128:89-99. crossref

54. Monés J, Srivastava SK, Jaffe GJ, et al. Risk of inflammation, retinal vasculitis, and retinal occlusion-related events with brolucizumab: post hoc review of HAWK and HARRIER. Ophthalmology 2021;128:1050-9. Crossref

55. Avery RL, Castellarin AA, Steinle $N C$, et al. Systemic pharmacokinetics and pharmacodynamics of intravitreal aflibercept, bevacizumab, and ranibizumab. Retina 2017;37:1847-58. Crossref

56. Kitchens JW, Do DV, Boyer DS, et al. Comprehensive review of ocular and systemic safety events with intravitreal aflibercept injection in randomized controlled trials. Ophthalmology 2016;123:1511-20. Crossref

57. Cheung CMG, Lai TYY, Ruamviboonsuk P, et al. Polypoidal choroidal vasculopathy: definition, pathogenesis, diagnosis, and management. Ophthalmology 2018;125:708-24. Crossref

58. Lee WK, Iida T, Ogura Y, et al. Efficacy and safety of intravitreal aflibercept for polypoidal choroidal vasculopathy in the PLANET Study: a randomized clinical trial. JAMA Ophthalmol 2018;136:786-93. Crossref

59. Wong TY, Ogura Y, Lee WK, et al. Efficacy and safety of intravitreal aflibercept for polypoidal choroidal vasculopathy: two-year results of the aflibercept in polypoidal choroidal vasculopathy Study. Am J Ophthalmol 2019;204:80-9. Crossref

60. Ohji M, Kobayashi M, Okada AA, Terano Y, Takahashi K. Intravitreal aflibercept treat-and-extend dosing for wet agerelated macular degeneration: ALTAIR 96-week results. Presentation at the 12th Asia-Pacific Vitreo-retina Society Congress; Seoul, South Korea. 14-16 December 2018.

61. Maruko I, Ogasawara M, Yamamoto A, et al. Two-year outcomes of treat-and-extend intravitreal aflibercept for exudative age-related macular degeneration: a prospective study. Ophthalmol Retina 2020;4:767-76. crossref

62. Hosokawa M, Morizane Y, Hirano M, et al. One-year outcomes of a treat-and-extend regimen of intravitreal aflibercept for polypoidal choroidal vasculopathy. Jpn J Ophthalmol 2017;61:150-8. crossref

63. Morimoto M, Matsumoto H, Mimura K, Akiyama H. Twoyear results of a treat-and-extend regimen with aflibercept for polypoidal choroidal vasculopathy. Graefes Arch Clin Exp Ophthalmol 2017;255:1891-7. Crossref

64. Morizane-Hosokawa M, Morizane Y, Kimura S, et al.Impact of polyp regression on 2-year outcomes of intravitreal aflibercept injections: a treat-and-extend regimen for polypoidal choroidal vasculopathy. Acta Med Okayama 2018;72:379-85. 